\title{
WHAT COMMON FACTORS ARE DRIVING INFLATION IN CEE COUNTRIES?
}

\author{
Aleksandra Halka, Grzegorz Szafranski*
}

\begin{abstract}
We investigate commonality and heterogeneity of inflationary processes in ten Central and Eastern European (CEE) countries over the period 2001-2013. The research is important for the analysis of monetary policy as it helps understand the origin of price formation from both sectoral and country perspective. With a multi-level factor model we decompose product-level inflation rates into the CEE region-wide, sector, country, country-sector, and idiosyncratic components. The outcomes indicate that CEE region-wide and country specific components are more persistent than sector and product-level components, which is in line with similar studies for core EU countries. Regional factors explain about $17 \%$ of variance in monthly price changes, which is more than any other factors (below $10 \%$ each). This result is at odds with the assumptions of many sectoral DSGE models and empirical evidence on the importance of sectoral price shocks in developed economies. The difference may be related to the conclusion that the first regional factor is associated with common disinflationary process that occurred in CEE economies in the 2000s, whereas the second one reveals significant correlations with global factors, especially commodity prices and euro area price developments.
\end{abstract}

Keywords: product-level inflation, CEE economies, multi-level factor model

JEL Classification: C38, C55, E31, E52, F62

\section{Introduction}

In the paper we argue that CEE countries on their road to the European Union have experienced similar inflationary pressures of economic and political origin (e.g. nominal convergence criteria). Starting from the 1990s, they have transformed their economies substantially to adjust to the challenges of EU common market. Therefore, in spite of some differences between these countries in terms of trade openness (export vs. domestic-oriented economies), economic structures (the extent of privatisation and competition), exchange rate regimes (from floating to euro-pegged, currency board and euro zone membership) etc., they still share some commonalities in price dynamics. The degree of common shocks dependence is an interest of monetary policy. It defines the extent of policy autonomy, especially in the context of exchange rate regimes introduced in the CEE countries. Answering the question, how important are the sectoral factors and domestic shocks in price setting, is also useful for better understanding of domestic and foreign sources of consumer inflation.

* Aleksandra Halka, National Bank of Poland, Poland (aleksandra.halka@nbp.pl);

Grzegorz Szafranski, National Bank of Poland, and Institute of Finance, The Faculty of Economics and Sociology, University of Lodz, Poland (grzegorz.szafranski@nbp.pl).

The views expressed herein are those of the authors and not necessarily of the institutions they represent. 
New-Keynesian sectoral dynamic stochastic general equilibrium (DSGE) models on price determination suggest that there is a stickiness in price setting at the firm level. These nominal rigidities, monopolistic competition and backward-looking price setting decisions are the building blocks of the New Keynesian paradigm. They generate lagged real effects of monetary interventions in DSGE policy-oriented models. There is, however, a wide microeconomic evidence suggesting that sectoral and individual prices are not sticky enough. Contrarily, they are very transient and volatile (see Bils and Klenow, 2004). Therefore, the co-existence of high persistence and low volatility in aggregate inflation with low persistence and high volatility observed in price dynamics at a microeconomic level is called an inflation volatility-persistence puzzle.

This volatility-persistence puzzle if it was a purely statistical phenomenon would call for high degree of price synchronization among sectors. ${ }^{1}$ The theoretical explanation of the puzzle is provided by Mackowiak and Wiederholt (2009) in a rational inattention model. In this model representative firms being under information processing constraints rationally allocate more attention to idiosyncratic shocks than to aggregate ones. Boivin et al. (2009) claim that distinguishing between sector specific and aggregate sources of price fluctuations is a key point in understanding the puzzle which is important, while calibrating sectoral DSGE models.

The literature of the past two decades suggests that there is a high degree of comovement in inflation rates across countries. A synchronization of price changes is observed among the countries strongly connected in terms of trade and financial market (see Borio and Filardo, 2007). At the aggregate level Ciccarelli and Mojon (2010) find that nearly 70\% of inflation volatility in 22 developed OECD countries in the period 1960-2008 was driven by a global factor. At the regional level Beck et al. (2009) show that common euro-area and country-specific factors are explaining a substantial part of inflation with idiosyncratic intra-regional variability playing a minor role. The literature that deals with these issues claims that inflation is a global phenomenon.

The existence of, both, global and domestic common factors driving inflation in CEE countries has already been advocated by several authors (e.g. Mackowiak, 2006; Stavrev, 2009; Krusper, 2012). Most of these studies analyse inflation at the aggregate level, without looking into the sectoral price determinants. We claim that in some sectors across CEE economies there are similar price vulnerabilities to market integration and globalization effects. In other sectors there are possibly relevant differences stemming from institutional matters like price-setting behaviour.

The empirical research on commonality in disaggregated inflation rates is scarce. Monacelli and Sala (2009) look for the contribution of international components that are responsible for the product-level inflation in 4 major OECD countries. Choueiri et al. (2008) using generalized dynamic factor model (GDFM) of Forni et al. (2000) analyse disaggregated HICP indices (with other macroeconomic variables) for 25 countries of the European

1 Other popular statistical explanation can be an aggregation bias or structural break in the mean of inflation (see Beck et al., 2011). 
Union in the first half of the 2000s. With the exception of another GDFM study by Stavrev (2009) the other researches on sectoral prices deal with comovements in the developed countries like US (Boivin et al., 2009; Mackowiak et al., 2009) or the euro area (Beck et al., 2011; Kaufmann and Lein 2013). Interestingly, when analysing disaggregated price indices common factors become less important than in the case of the aggregate data (cf. Boivin et al., 2009; Beck et al., 2011).

In the empirical part we decompose COICOP product-level HICP inflation rates of the CEE countries into aggregate, country, sector and country-sector specific common components, and idiosyncratic components. We also document the volatility-persistence puzzle in a unique product-level decomposition of HICP components. Our method is related to the iterative non-parametric PCA-based method of Beck et al. (2011) as we decompose common factors from overlapping data blocks but with a different hierarchical structure of the factor model. The second aim of our research is the interpretation of the forces behind unobserved common factors. We also provide an economic discussion on the possible sources of comovements in sectoral prices.

\section{The Hierarchical Factor Model}

Most of inflation decomposition studies, which are focussed on extracting global components of inflation (e.g. Ciccarelli and Mojon, 2010) or document the inflation volatilitypersistence puzzle (e.g. Boivin et al., 2009), rely on a static representation of dynamic factor model. The decomposition of inflation to sectoral and global components is mostly based on a basic framework of the first-order factor model. The simple specification is suitable to introduce the dynamic relationship between common factors and observables (like in a FAVAR approach by Boivin et al., 2009) but it has a major drawback. It implicitly assumes that price dynamics is not shared within a country or inside a sector. Residuals from the first-order factor models capture not only idiosyncratic shocks but sectoral, geographical, country specific components, and other measurement errors as well.

The data sets of overlapping sectoral and geographical dimensions should be better analysed with a higher-order hierarchical factor model. Some authors already have used two-level factor model to decompose inflation into common (global) and sectoral or geographical factors (e.g. Krusper, 2012; or Altissimo et al., 2011). Simple second-order factor models have been already used in the analyses of regional inflation rates $-e . g$. Beck et al. (2009) and Krusper (2012) leading to the following decomposition of sectoral inflation rates, $\pi_{c, r, t}$, in a country $c$ and a region $r$ :

$$
\pi_{c, r, t}=\lambda_{c, r}^{a} f_{t}^{a}+\lambda_{c, r}^{r} f_{t}^{r}+u_{c, r, t}
$$

where $f_{t}^{a}$ represents global (aggregate) common factors, $f_{t}^{r}$ is a factor specific to a subset of countries (e.g. CEE) or regions in a given country $r, \lambda_{c, r}^{a}$ and $\lambda_{c, r}^{r}$ are factor loadings, and $u_{c, r, t}$ is an idiosyncratic white-noise.

Different sets of dimensions $\{c, r\}$ in $\pi_{c, r, t}$ are applied in the literature depending on the focus of the research and the data availability. For example, Krusper (2012) in a panel 
of HICP inflation rates for EU27 is interested in a regional component of inflation for 10 CEE countries, hence he defines $c$ as a country, and $r$ as a region. In another study Beck et al. (2009) analyse regional overall HICP inflation rates in NUTS region $c$ of EMU country $r$.

In our study we decompose product-level inflation rates in CEE countries (for more details, see section Data) with a three-level hierarchical factor model. The sectors are defined at a superior level (5 broad groups of consumption goods: durables, semidurables, non-durables, food and services) and subordinate level (mostly 4-digit COICOP items). Geographical dimension consists of 10 countries. Formally, we apply a static representation of a factor model for product-level log-price changes $\left(\pi_{c, i, t}\right)$ offering the following economic interpretation for the unobserved common factors:

where:

$$
\pi_{c, i, t}=\alpha_{c, i} f_{t}^{a}+\beta_{c, i} f_{t}^{s}+\gamma_{c, i} f_{t}^{c}+\delta_{c, i} f_{t}^{c s}+e_{c, i, t}
$$

$c=1, \ldots, 10$ denotes a country, $i=1, \ldots, N_{c}$ is a product-level item in country $c$, and $t=1, \ldots, T$ is a time dimension (months);

$f_{t}^{a}$ is a vector of $k_{a}$ aggregate (CEE region-wide) factors, which are common to all items (i) and which are potentially related to common EU trade policy or other external shocks e.g. to specific commodity prices;

$f_{t}^{s} \quad$ a vector of $k_{s}$ factors specific to sector $s, i \in s$, (group of goods like durables), which are potentially related to sectoral policies, shocks in oil market, changes to consumption patterns or differences in exchange rate pass-through effects on tradables; $f_{t}^{c} \quad$ a vector of $k_{c}$ country-specific factors representing such events in country economic policies as VAT changes, currency depreciation, etc.;

$f_{t}^{c s}$ a vector of $k_{c s}$ country and sector-specific factors $(i \in S)$ that affect only prices in a sector $s$ of a country $c$ (like energy prices in Poland, or food prices in Romania); $\alpha_{c, i}, \beta_{c, i}, \gamma_{c, i}, \delta_{c, i}$ are vectors of factor loadings specific to each factor for item $i$ in country $c$; and $e_{c, i, t}$ represent idiosyncratic terms orthogonal to other factors.

The hierarchical factor model is a linear factor model with orthogonal factors and zero restrictions on parameters at factors not specific to a given cross-section dimension $\{c, i\}$. As dimensions are overlapping and hierarchical, model (2) calls for special methods to estimate loadings and extract common factors in an iterative way. The number of factors in model (2) may be established by the cumulative percentage of variance explained by factors or with more formal information criteria (Bai and $\mathrm{Ng}, 2002$ ). The decomposition of lower-order factors, however, is conditional on the number of factors extracted at higher-order level. Selecting more than one factor at each level also poses serious identification problems. Thus, in the empirical part of the study we select only one common factor at lower-order levels $\left(k_{c}=k_{s}=k_{c s}=1\right)$. We perform sensitivity analysis to the choice of $k_{a}$ (see Halka, Szafranski, 2015, Appendix).

The novel contribution of our approach to the analysis of disaggregated sectoral inflation rates relies in a unique decomposition of product-level price dynamics from overlapping cross-sections (geographical and sectoral). Another important distinction is an interpretation of sector-specific factors at this level of data disaggregation. Firstly, our 
sectors are much broadly defined than in analogous studies for developed countries (Beck et al., 2011). Secondly, the information on comovements comes from the product-level HICPs. According to our knowledge this level of disaggregation was not analysed with an overlapping third-order hierarchical factor model until now.

In estimation we adapt a non-parametric method of Beck et al. (2011), which is capable of treating an overlapping data structure in a coherent way. In the first step we use full sample to estimate CEE region-wide factors, $f_{t}^{a}$, by the method of principal components (PC). In the second step we regress $\pi_{c, i, t}$ on the estimates $\hat{f}_{t}^{a}$ to obtain OLS residuals. From these residuals (demeaned across countries) we extract sector-specific factors $\hat{f}_{t}^{s}$ by PC method in each sector $s .{ }^{2}$ In the third step we run regressions of $\pi_{c, i, t}$ on factors $\left\{\hat{f}_{t}^{a}, \hat{f}_{t}^{s}\right\}$ and calculate OLS residuals. From these residuals country-specific factors $\left(\hat{f}_{t}^{c}\right)$ are PC-extracted in each country subsample. Analogously, by regression on $\left\{\hat{f}_{t}^{a}, \hat{f}_{t}^{s}, \hat{f}_{t}^{c}\right\}$ and PC method we extract country-sector factors ( $\hat{f}_{t}^{c s}$ ) separately in each subset of residuals for a given country and sector. Finally, with PC method applied to idiosyncratic residuals of model (2) we estimate one-factor CEE region-wide components (Idios. COICOP in Table 3, 4, 5), specific for each product-level item.

\section{Data}

We analyse all sectoral components of monthly Harmonized Index of Consumer Prices (HICP) from 10 Central and Eastern European (CEE) countries: Bulgaria (BL), the Czech Republic (CZ), Estonia (EE), Hungary (HU), Latvia (LV), Lithuania (LT), Poland (PL), Romania (RO), Slovakia (SK) and Slovenia (SI) for the period January 2001 - September 2013. The original one-base $(2005=100)$ price indices come from the Eurostat website (ec.europa.eu/eurostat/web/hicp/data). The selection of countries reflects the choice of many authors interested in disentangling common- and country-specific factors across new EU members (see Stavrev, 2009; Krusper, 2012).

To capture the co-movements in inflation rates across countries and sectors we employ the HICP indices at the disaggregation level up to four digits according to Classification of Individual Consumption According to Purpose (COICOP), which we call, in short, product-level data. When analysing sector-specific factors at superior level we consider 5 broad COICOP end-use categories of the Eurostat (named sectors for convenience). These are services, food (which includes beverages, alcohol and tobacco), and three non-food good categories: durables, semi-durables, non-durables.

The original database consists of 94 product-level COICOP categories but some of them are excluded from the full sample. These are a few categories of the consumption basket with a missing values at the beginning of the sample due to the late acquisition of good quality data. We also omit COICOP categories with market prices observed only in a few of 10

2 The necessary modification in the iterative procedure compared to the two-step approach of Beck et al. (2011) is iteration between steps of obtaining different lower-order factors. Instead of countryspecific factors we estimate sector-specific factors first. We also repeat the lower-order factor extraction procedure (from step 2 to step 3 ) until convergence. 
CEE countries (like combined passenger transport or maintenance and repair of other major durables for recreation and culture). We skip another 51 time series with zero monthly price changes in more than $25 \%$ of the sample periods. These are mainly administered prices, although different items are referred under this name in different countries and across time. The administered prices are fixed for a considerable period of time between price decisions of country regulator, hence they are not suitable for correlation analysis as well.

Finally, we employ a balanced panel of 776 HICP-component series (from 74 components in Estonia to 82 in the Czech Republic) over 154 consecutive months (see Table 1). The selected product-level HICP components are seasonally adjusted (SA) by a Tramo/Seats automatic procedures. Due to high kurtosis the data are corrected for outliers by winsorizing non-typical observations beyond $5^{\text {th }}$ and $95^{\text {th }}$ deciles.

Table 1 | Descriptive Statistics (simple averages) of Monthly Seasonally Adjusted Product-Level HICP Inflation Rates by Sector for the Period January 2001 - September 2013

\begin{tabular}{|l|r|r|r|r|r|r|}
\hline & Durables & $\begin{array}{c}\text { Semi- } \\
\text { durables }\end{array}$ & $\begin{array}{c}\text { Non- } \\
\text { durables }\end{array}$ & Food & Services & Total \\
\hline \multicolumn{7}{|c|}{ Logarithmic changes per month in pp. } \\
\hline No of series & 114 & 129 & 129 & 149 & 255 & 776 \\
\hline Mean & -0.180 & 0.109 & 0.402 & 0.373 & 0.428 & 0.174 \\
\hline Median & -0.055 & 0.097 & 0.259 & 0.227 & 0.271 & 0.185 \\
\hline St. dev. & 1.093 & 0.893 & 1.692 & 1.836 & 1.874 & 1.622 \\
\hline Skewness & -0.549 & 0.686 & 1.812 & 1.606 & -0.473 & 0.688 \\
\hline Kurtosis & 23.3 & 84.3 & 38.0 & 43.0 & 520.5 & 327.4 \\
\hline AR(1) & 0.193 & 0.032 & 0.127 & 0.250 & 0.139 & 0.147 \\
\hline
\end{tabular}

Note: AR(1) is a mean of first-order autoregression coefficients across product-level data.

Source: own calculations.

A substantial heterogeneity is observed in the sample among monthly price changes across different sectors (see Table 1). Services, non-durables and food are among the sectors with the highest average monthly inflation, close to $0.4 \%$. Unsurprisingly, these sectors are among those with the highest price volatility. The lowest monthly inflation is recorded for semi-durables $(0.1 \%)$ and durables (negative, $-0.2 \%$ ). Countries with higher inflation are also characterized by higher inflation persistence as measured by a first-order autoregression coefficient AR(1) - see Table 2. Romania is a clear example of this stylized fact with average monthly inflation at $0.6 \mathrm{pp}$. and inflation persistence at 0.7 . The Czech Republic with non-persistent and very low inflation is an evidence at the other end of the scale.

Product-level inflation rates when compared to the aggregate data (see Table 2) are much more volatile. Median of standard deviations of the aggregate HICP across countries is $0.4 \mathrm{pp}$. versus $1.6 \mathrm{pp}$. at the product-level. On the other hand, average inflation persistence 
is two times bigger at the aggregate level than at the product level (0.34 versus 0.15$)$. This simple observation in the cross-section of CEE countries is in line with the volatilitypersistence puzzle observed in many advanced economies (see Introduction).

Table 2 | Descriptive Statistics of Monthly Seasonally Adjusted Product-Level HICP Inflation Rates vs. Aggregate Inflation (HICP all items) by Countries for the Period January 2001 - September 2013

\begin{tabular}{|l|c|c|c|c|c|c|c|c|r|r|r|}
\hline & BG & CZ & EE & HU & LT & LV & PL & RO & SI & SK \\
\hline \multicolumn{7}{|c|}{ Product-level inflation rates (simple averages of log changes per month in pp.) } \\
\hline Sectors & 77 & 82 & 74 & 78 & 80 & 76 & 78 & 78 & 75 & 78 \\
\hline Mean & 0.306 & 0.094 & 0.313 & 0.337 & 0.182 & 0.281 & 0.172 & 0.622 & 0.218 & 0.194 \\
\hline St. dev. & 1.721 & 1.281 & 1.865 & 1.360 & 1.571 & 1.788 & 1.415 & 1.402 & 2.116 & 1.509 \\
\hline AR(1) & 0.257 & 0.020 & 0.089 & 0.113 & 0.157 & 0.045 & 0.321 & 0.717 & -0.046 & 0.189 \\
\hline \multicolumn{7}{|c|}{ Aggregate inflation (log changes per month in pp.) } & & \\
\hline Mean & 0.388 & 0.178 & 0.330 & 0.378 & 0.252 & 0.402 & 0.217 & 0.718 & 0.290 & 0.308 \\
\hline St. dev. & 0.556 & 0.328 & 0.404 & 0.501 & 0.432 & 0.381 & 0.252 & 0.633 & 0.372 & 0.401 \\
\hline AR(1) & 0.341 & 0.227 & 0.411 & 0.595 & 0.347 & 0.233 & 0.401 & 0.652 & 0.211 & 0.280 \\
\hline
\end{tabular}

Note: See Table 1.

Source: own calculations.

\section{Results}

We present the results of estimating three-level factor model (2) on a balanced sample with a disclaimer that they are dependent on the number of factors selected at each level of hierarchical data structure including the number of aggregate factors. The more aggregate factors are selected the less variability remains for explaining inflation rates with lowerorder components. Thus, after the analysis of dominating eigenvalues on the scree plot the results with two CEE region-wide factors $\left(k_{a}=2\right)$ have been selected. ${ }^{3}$ The decision to select one factor for each lower-order breakdown $\left(k_{c}=k_{s}=k_{c s}=1\right)$ also guarantees that sector, country, and country-sector specific factors are identified up to a sign and variance (a local identification property).

\section{Factor decomposition}

From our decomposition we find that all common factors explain on average $36.5 \%$ of variance in monthly inflation at the product level (see Figure 1 and Table 3). The model is the most adequate for describing inflation rates in Romania and the least fitted in the case

3 The scree plots and the results for two alternative factor specifications (with 3 factors and with inflation in year-over-year terms) are presented in Halka, Szafranski (2015) in Appendix. 
of Slovenia. On average the most important are two aggregate (CEE region-wide) factors which contribute to a half of the total variance explained (17.3\%). Less important are country $(6.5 \%)$ and sector specific (3.1\%) components. The country-sector specific components explain $9.6 \%$ of temporal variation which is more than explained part of country specific and sector specific components altogether. Additionally, common shocks to single COICOP items (Idios. COICOP in Figure 1 and Table 3) contribute to $10.9 \%$ of variance.

The first aggregate factor explains $10.8 \%$ of variation in sectoral prices, whereas the second one adds $6.5 \%$. The contributions of CEE region-wide component vary between different countries and sectors considerably (see Figure 1 and Appendix). It is the most prominent factor in Romania (explaining 55\% of price variability), and the least important in Estonia (10\%), the Czech Republic (8\%) and Slovenia (6\%). ${ }^{4}$ In other countries the fraction of explained variance is between 13\% (Poland) and 18\% (Bulgaria). The CEE region-wide component explains from $11 \%$ of variance in food and non-durable sector to $24 \%$ in services being the most important price determinant in each of them.

\section{Figure 1 | Factor Model Decomposition of Variance of Product-Level Inflation (averages across countries, log-changes in mom terms)}

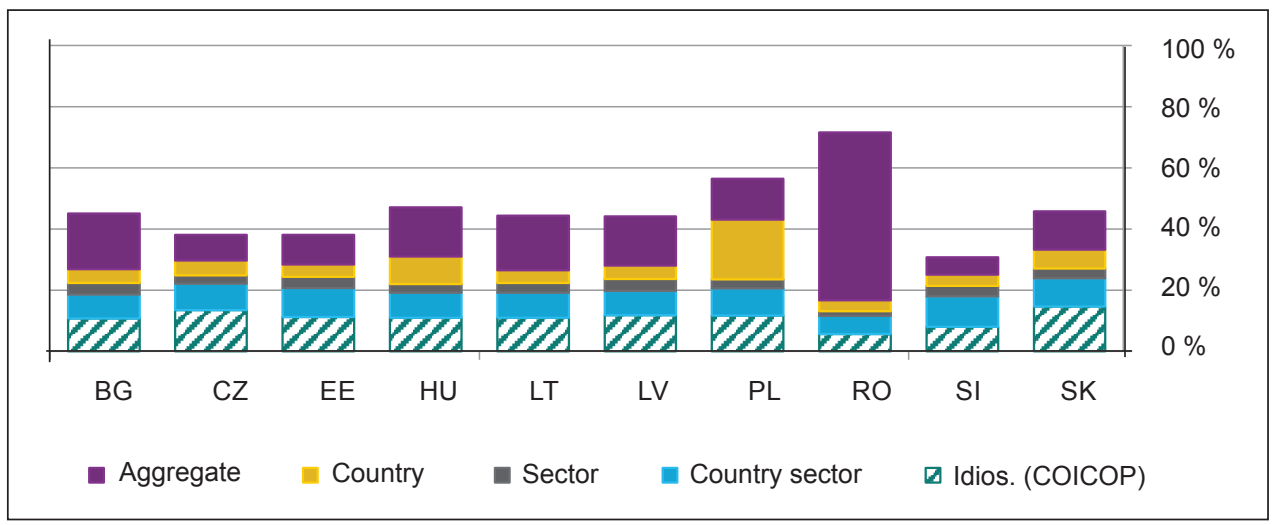

Source: Authors' calculations in model (2).

The average statistics give an overall view on relative importance of regional and country factors in explaining product-level inflation rates. There are, however, prices in some 4-digit COICOP categories that are strongly dependent on a single factor (more than $50 \%$ of variance explained). These are, for example, prices of liquid fuels in euro-pegged countries Slovenia, Bulgaria and Slovakia linked to sectors specific factors, garments in the Czech Republic and Hungary dependent on country-sector specific shocks or vegetables in Latvia and the Czech Republic determined by average prices of vegetables across CEE.

4 The possible reason why Slovenian economy is not under the dominant force of common CEE region-wide factors is the starting period of economic transition. In the 1990s prices in Slovenia were comparable to the Western Europe and the price convergence as one of the forces driving disinflation in CEE countries was not substantial here. 
Table 3 | Descriptive Statistics of Common and Idiosyncratic Components in Three-Level Factor Model (2): Volatility (log monthly changes), Persistence and Fraction of Variance Explained

\begin{tabular}{|c|c|c|c|c|c|c|}
\hline & Aggregate & Country & Sector & $\begin{array}{l}\text { Country- } \\
\text { sector }\end{array}$ & Idiosyncratic & $\begin{array}{l}\text { Idios. } \\
\text { (COICOP) }\end{array}$ \\
\hline \multicolumn{7}{|c|}{ Volatility (standard deviations in pp.) } \\
\hline Mean & 0.187 & 0.120 & 0.120 & 0.180 & 0.578 & 0.221 \\
\hline Median & 0.152 & 0.077 & 0.047 & 0.105 & 0.402 & 0.129 \\
\hline Min & 0.002 & 0.000 & 0.000 & 0.000 & 0.025 & 0.000 \\
\hline Max & 0.799 & 1.380 & 3.176 & 2.295 & 4.691 & 3.788 \\
\hline St. dev. & 0.139 & 0.143 & 0.267 & 0.232 & 0.619 & 0.351 \\
\hline \multicolumn{7}{|c|}{ Persistence, AR(1) coefficient } \\
\hline Mean & 0.974 & 0.630 & 0.315 & 0.199 & 0.071 & 0.148 \\
\hline Median & 0.975 & 0.680 & 0.331 & 0.204 & 0.058 & 0.121 \\
\hline Min & 0.968 & -0.145 & 0.071 & -0.240 & -0.543 & -0.285 \\
\hline Max & 0.980 & 0.880 & 0.551 & 0.705 & 0.673 & 0.628 \\
\hline St. dev. & 0.004 & 0.267 & 0.180 & 0.213 & 0.179 & 0.211 \\
\hline \multicolumn{7}{|c|}{ Variance explained (in \%) } \\
\hline Mean & 17.3 & 6.5 & 3.1 & 9.6 & 64.7 & 10.9 \\
\hline Median & 8.9 & 2.7 & 1.0 & 5.3 & 67.9 & 7.5 \\
\hline Min & 0.0 & 0.0 & 0.0 & 0.0 & 3.0 & 0.0 \\
\hline Max & 91.0 & 54.5 & 55.7 & 57.6 & 99.0 & 62.8 \\
\hline St. dev. & 20.7 & 9.4 & 6.7 & 10.9 & 22.2 & 11.1 \\
\hline
\end{tabular}

Source: Authors' calculations.

The interpretation of country-sector specific component is troublesome. It may be interpreted as a domestic part of sector-specific price variation being the result of sectororiented economic policy or a particular structure of a domestic economy. Equivalently, it may be understood as a sectoral component, which is interpreted as country-specific because inflation rates are calculated in domestic currencies or because the sectors in a country are influenced by country-wide regulations (e.g. fiscal policy). We follow the second interpretation calling sector and country-sector specific components as ones of sectoral origin. Following this interpretation the overall contribution of sectoral factors is $13 \%$ on average, which is lower than the contribution of CEE region-wide factors, but it still explains a considerable part of inflation variability at the product level. 
The total fraction of variance explained in our study is hard to compare with the results of others because of different methods applied or different level of data aggregation. Stavrev (2009) using GDFM framework for an analogously defined product-level prices finds that in the period 1998-2008 one dynamic CEE region-wide factor explains about $65 \%$ of overall variance in year over year (yoy) terms. This result is much higher than $17 \%$ of mom price changes accounted in our study or 32\% when yoy changes are used (see results in Appendix of Halka, Szafranski (2015). Yet, GDFM in frequency domain corresponds to an infiniteorder lag polynomial on factors in time domain. Contrarily, our specification with a different overlapping geographical and sectoral structure is static. In a corresponding hierarchical factor model with 52 regions of 5 EMU countries by Beck et al. (2011) the variance explained by common factors is about $53 \%$. However, HICP indices they use are at higher level of sectoral aggregation (11 sectors in their paper versus 82 four-digit COICOP groups in our sample).

Our decomposition is useful in describing the nature of shocks to consumer price changes at the product level. The magnitude of CEE region-wide shocks with average mom volatility estimated at $0.19 \mathrm{pp}$. seems to be an important source of inflation fluctuations next to countrysector specific disturbances $(0.18 \mathrm{pp}$. $)$ - see Table 3 . Country and sector specific factors generate shocks of a lower magnitude, $0.12 \mathrm{pp}$. each. Although there are 10 different countries and 5 different sectors under research, the sample is much more heterogeneous in terms of shock decomposition across sectors than across countries (with a standard deviation of volatility at 0.27 and $0.14 \mathrm{pp}$., respectively) which could be a statistical evidence of ongoing integration process. We also find that despite thorough procedure of data preparation (including data winsorizing) still idiosyncratic shocks play a major role in price dynamics at the product level with a median of standard deviations close to $0.40 \mathrm{pp}$. per month.

Not only the magnitude of shocks to inflation but also their persistence, i.e. for how long they persist, is of a big value to the results of shocks decomposition. The most persistent are CEE region-wide shocks. With first-order autocorrelation of 0.97 this is almost non-stationary part of variation extracted from the full sample. The number of crosssection units in the data panel guarantees that the results are not spurious but they are still remarkably high. Also the country components are very persistent on average (with a median $\mathrm{AR}(1)$ coefficient at 0.68). It is a homogenous result among CEE countries, except for Slovenia, where the persistence of (not very important) country specific component is close to 0 . The results on persistence are generally in line with similar studies for core EU countries (Beck et al., 2011), but the degree of persistence is more than three times bigger. In line with many other studies of inflation at sectoral (e.g. Beck et al., 2011) and productlevel data (Stavrev, 2009) common aggregate factors exhibit high persistence.

Unlike in any decomposition studies for developed countries common aggregate components are as volatile as any other components of country or sectoral origin with the only exception of idiosyncratic component. It means that big shocks in CEE countries are those specific to single items and to the regional ones which come next.

At the last step of decomposition we have also extracted the part of variance common across CEE countries to price changes in a given four-digit COICOP group. This 
common component (Idios. COICOP in Figure 1 and Table 3) explains 1/6 of price changes being more important than sector specific component. It is also the most volatile and nonuniform component of product-level inflation rates.

\section{CEE region-wide factors}

We investigate into the nature of common factors by a cross-correlation analysis supported with some literature studies. We consider country and regional macroeconomic series, both, in nominal (aggregate consumer prices - HICP and producer prices - PPI, exchange rates, commodity prices) and real terms (economic activity indicators: industrial output, unemployment rates, PMIs). ${ }^{5}$

The results indicate that the first factor is not strongly contemporaneously correlated with average aggregate inflation in CEE countries (see Figure 1, left panel) or any other single variable under investigation. Concluding from its dynamics it may be associated with the disinflationary processes that occurred in the early 2000s in some of CEE economies which led to a downturn in inflation expectations. Disinflation was a common phenomenon at that time in some of the CEE countries, especially Bulgaria and Romania $^{6}$, and in others it was observed only in some HICP components (e.g. food and durables). This process can be attributed to several factors. One is an inflation targeting strategy, which lowered inflation expectations in the countries with an initially low level of consumer prices as compared to the EA. The other is structural reforms conducted in the 1990s, which led to a change in price setting behaviour of firms. The disinflation may be also attributed to the globalization effects. First, growing openness of the CEE countries leads to the decrease in domestic firms mark-ups, second as pointed out by Pehnelt (2007), a relocation of production to the countries with relatively lower labour costs decreases the cost of imported goods (see Allard, 2007, for Poland).

The second common factor can be recognized as a price reaction in the CEE countries to the changes in the global economy, what we interpret as an imported part of the country's inflation (see Figure 2). The strongest contemporaneous correlation of HICP inflation with this factor ( 0.4 or more) is found in the group of countries with currency peg or currency management like the Baltic countries and Bulgaria. The second factor fluctuates, similarly like HICP in the EA, around zero level up to the end of 2006, then it rises as the global commodity prices picked up and in 2009, with the beginning of the financial crisis, it declines. Subsequently, starting from the beginning of 2010, it rises again, and from mid-2011 it is in a downward trend. Besides, it also correlates with unemployment (in BG and PL above 0.5), and moderately with a global PMI (0.2). Therefore we state that not only global inflation factors drive inflation in CEE countries, but also other

5 The results of bulk correlation analysis are available on request. To avoid problems of a spurious correlation the calculations are also performed on first differences of original variables which results in very low correlation coefficients.

6 When eliminating Romania from the sample we would receive similar results - two comparable common factors, but in a reversed order of importance and with slightly lower part of overall variance explained. 
macroeconomic processes including business cycle. However, this reaction occurs mostly via price developments in EA economies.

Figure 2 | First (left panel) and Second (right panel) CEE Region-Wide Factor Compared to yoy HICP for the CEE-10 (left panel) and Euro Area (right panel)

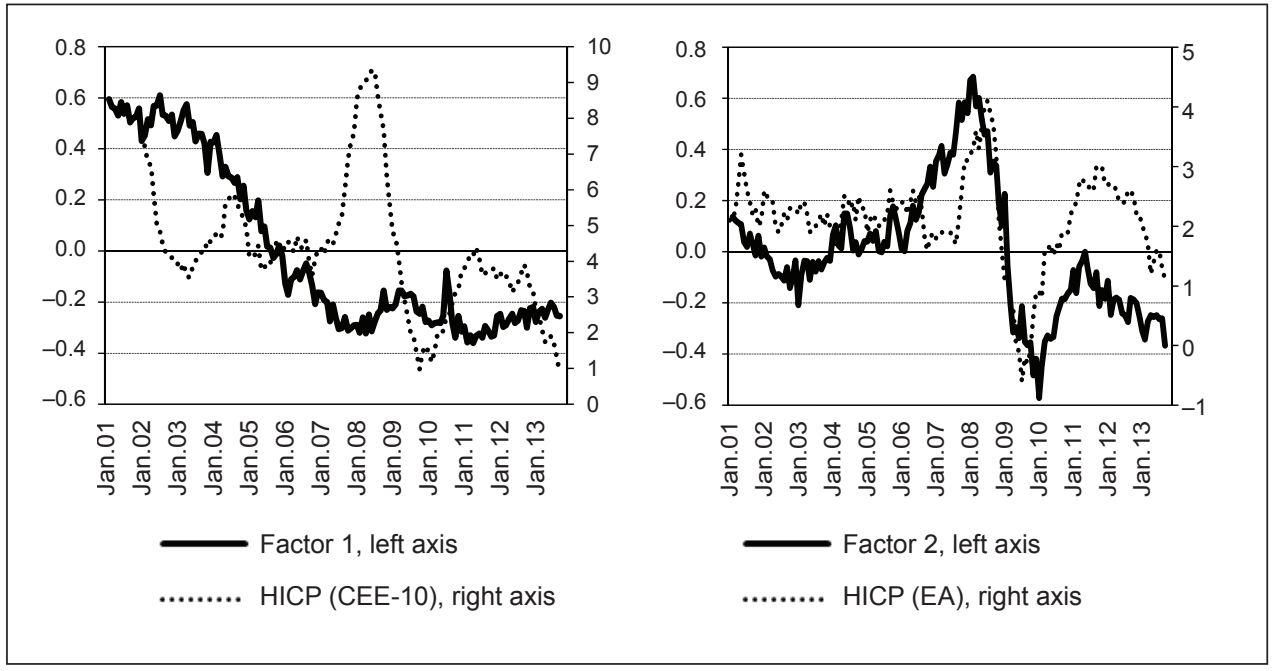

Source: Author's calculations, Eurostat data.

\section{Country specific factors}

The correlations of country specific factors for most of the CEE countries show that one of the most important determinants of inflation is an unemployment rate in a particular country (correlations from 0.20 to 0.25 ), with the exception of Romania, Slovenia and Slovakia. The biggest correlations of domestic factor with the EA and US unemployment are found in Bulgaria, the Baltic states and Poland (0.4 or more). Moreover, country factor is also correlated with domestic core inflation i.e. HICP net of food and energy.

As expected, country specific factors are influenced mostly by the domestic variables, however, external factors are not negligible in some of CEE countries. For example, country specific factor for Slovakia exhibits moderate correlation (at 0.2 ) with the global economy conjuncture measured by the PMI global index. Slovakia is also linked with a global commodity market through energy and industry commodities as among the analysed countries it is the most dependent on the imports of energy commodities (10 pp. above the EU average, European Commission, 2013) and its industry is very energy-intensive. Large foreign investments to energy-intensive sectors like chemical engineering and automotive or machinery construction contribute to a significant dependency of Slovak economy on these commodities.

In general, countries with higher GDP per capita, higher productivity and economy's openness have on average higher volatility and lower persistence of the country specific 
factor (which is especially visible in the case of the Baltic countries). This outcome can be attributed to the fact that prices in those countries are more flexible and change more often than in the EA (cf. results for Estonia obtained by Dabušinskas and Randveer, 2006). For small open economies quick adjustment to changing external economy is an important factor as it helps maintain the competitiveness of the domestic companies. In contrast, companies in the countries with big domestic markets like Poland, can afford not to adjust their prices so quickly.

Additionally, the outcomes of the research indicate that exchange rate regime plays a role. Countries with the fixed or pegged exchange rate (like the Baltic countries or SI, BG) exhibit higher volatility of country specific components, what suggests that floating exchange rate and independent monetary policy may to some extent act as a shock absorber and prevent against sharp price movements during period of global perturbations.

\section{Sector specific factors}

Developments of food prices in countries of the CEE region are driven by the changes in global commodity prices and domestic conditions. On the one hand, growing importance of the world commodity markets and the increasing openness of the CEE economies causes stronger price reaction to the movements of commodity prices. On the other hand, recent research on the sensitivity of the HICP components to the output gap in Poland provides evidence that more than half of food indices react to the changes in the domestic output gap (see Halka and Kotlowski, 2014). Similar observation is valid for other non-durable goods, which include mainly the energy products. The prices in this sector are determined by energy commodity prices (i.e. oil, gas and coal). The factors of second importance are producer prices (PPI) and unemployment in the EA. Correlation with PPI may result from its dependence on commodity prices. However, the correlation of non-durables common factor with economic conditions of the EA proves that it is an important trading partner of CEE countries.

The common price factor of services, according to the expectations, reveals the moderate correlation with unemployment rates in the domestic economy (about 0.2). Services are rather a heterogeneous group which consists of components influenced by strong competition (like communication or insurance services) or partly administered (like services related to dwellings). Those components hardly react to changes in external or domestic economy (compare Halka and Kotlowski, 2014).

Surprisingly, there is hardly any influence of the changes in the global or domestic economic activity on factors specific to durable and semi-durable goods. It is probably due to the fact, that these groups are influenced by the globalization process. Moreover, some of these goods are also under strong impact of technological development (e.g. telephone equipment). Both factors, globalization and technological development, entail lowering of prices no matter what is the phase of the business cycle.

\section{Conclusions}

The decomposition of product-level inflation rates shows that two CEE-region wide factors explain about $17 \%$ of variance unequally distributed between countries and sectors. It is 
the most important price determinant in Romania (55\% of inflation variability) and less important in Estonia, the Czech Republic and Slovenia where idiosyncratic components explain about $3 / 4$ of price variability. The contributions of regional components vary across sectors from $11 \%$ in food and non-durable goods to $24 \%$ in services. The other factors i.e. country-sector specific (with contribution of $9.6 \%$ ), country $(6.5 \%$ ), and sector specific $(3.1 \%)$, although not being dominant, are still the most important determinants of inflation in some countries (like country factor in Poland) or some COIOP categories (see section Results).

Wealso document the inflation volatility-persistence puzzle in CEE countries and support it with the results of factor model-based decomposition. Firstly, in line with similar studies for core EU countries, regional component is very persistent and the country component is quite persistent too ( 0.97 versus 0.68 in terms of AR(1) coefficient). Secondly, large contributions of regional and country specific factors diminish the discrepancy of inflation persistence at the aggregate level vs. disaggregate level. Thirdly, still inflation in CEE countries is more persistent at the aggregate than at the sectoral level. Lastly, inflation rates at the product level are the more volatile the bigger contribution of idiosyncratic shocks in factor decomposition. Slovenia and Estonia are examples of volatile product-level inflation with shock decomposition dominated by idiosyncratic part. Romania is an example on the other end of the scale. The puzzling result of our research is high volatility of macroeconomic components relative to sectoral ones, which calls the explanation provided by the model of rational inattention into the question.

The correlation analysis indicates that the first regional factor may be associated with the disinflationary processes that occurred in CEE countries, whereas the second one reveals correlations with some global factors, especially commodity prices and inflation in the EA.

The results of our research may be useful for the monetary authorities in CEE countries. The outcomes underline the importance of the domestic conditions in the price setting behaviour, which implies effectiveness of the domestic monetary policy in countries with autonomous monetary policy (including exchange rate). Moreover, the decomposition results indicate that the set of factors influencing inflation are wide and mixed for different components of CPI basket. Such conclusion reinforces the belief prevailing in the inflation targeting strategy that, when deciding on the optimal shape of monetary policy, one should base the decision on the entire spectrum of economic variables. 


\section{Appendix}

\section{Decomposition Results of the Base Case with Two Aggregate Factors}

Volatility, Persistence and Variance Explained by Common Factors, Cross-Country Breakdown (log monthly changes)

\begin{tabular}{|c|c|c|c|c|c|c|c|c|c|c|}
\hline & BG & $C Z$ & EE & HU & LT & LV & PL & RO & SI & SK \\
\hline \multicolumn{11}{|c|}{ Volatility (standard deviations in pp.) } \\
\hline Aggregate & 0.221 & 0.106 & 0.199 & 0.157 & 0.232 & 0.291 & 0.092 & 0.277 & 0.152 & 0.148 \\
\hline Country & 0.112 & 0.082 & 0.154 & 0.134 & 0.131 & 0.145 & 0.086 & 0.081 & 0.161 & 0.104 \\
\hline Sector & 0.162 & 0.085 & 0.169 & 0.090 & 0.126 & 0.168 & 0.071 & 0.067 & 0.178 & 0.101 \\
\hline Country-sector & 0.201 & 0.126 & 0.217 & 0.135 & 0.166 & 0.228 & 0.095 & 0.127 & 0.256 & 0.154 \\
\hline Idiosyncratic & 0.620 & 0.436 & 0.801 & 0.482 & 0.648 & 0.793 & 0.345 & 0.367 & 0.845 & 0.479 \\
\hline COICOP & 0.232 & 0.189 & 0.281 & 0.193 & 0.253 & 0.317 & 0.152 & 0.133 & 0.252 & 0.212 \\
\hline \multicolumn{11}{|c|}{ Persistence, AR(1) coefficient } \\
\hline Aggregate & 0.973 & 0.974 & 0.973 & 0.975 & 0.974 & 0.971 & 0.976 & 0.978 & 0.975 & 0.975 \\
\hline Country & 0.698 & 0.635 & 0.621 & 0.660 & 0.690 & 0.592 & 0.883 & 0.849 & -0.135 & 0.658 \\
\hline Sector & 0.381 & 0.382 & 0.381 & 0.382 & 0.380 & 0.380 & 0.386 & 0.378 & 0.374 & 0.377 \\
\hline Country-sector & 0.297 & 0.260 & 0.202 & 0.080 & 0.092 & 0.049 & 0.378 & 0.523 & -0.021 & 0.367 \\
\hline Idiosyncratic & 0.119 & 0.037 & 0.024 & 0.070 & 0.049 & -0.010 & 0.139 & 0.234 & -0.053 & 0.095 \\
\hline COICOP & 0.153 & 0.146 & 0.149 & 0.148 & 0.147 & 0.148 & 0.151 & 0.148 & 0.144 & 0.148 \\
\hline \multicolumn{11}{|c|}{ Variance explained (in \%) } \\
\hline Aggregate & 18.3 & 8.5 & 9.8 & 16.1 & 17.8 & 16.1 & 13.4 & 54.8 & 5.6 & 12.5 \\
\hline Country & 4.6 & 4.7 & 4.0 & 9.0 & 4.1 & 4.4 & 19.6 & 3.6 & 3.7 & 6.2 \\
\hline Sector & 3.7 & 2.8 & 3.7 & 2.7 & 3.2 & 3.9 & 2.9 & 1.5 & 3.4 & 3.2 \\
\hline Country-sector & 7.8 & 8.7 & 9.5 & 8.2 & 8.2 & 7.9 & 8.9 & 6.0 & 10.0 & 9.2 \\
\hline Idiosyncratic & 65.6 & 75.3 & 73.1 & 63.9 & 66.5 & 67.8 & 55.1 & 34.0 & 77.3 & 68.7 \\
\hline COICOP & 10.7 & 13.4 & 11.2 & 11.0 & 11.0 & 11.8 & 11.7 & 5.6 & 8.0 & 14.7 \\
\hline \multicolumn{11}{|c|}{ Squared loadings at two aggregate factors } \\
\hline Aggregate 1 & 0.059 & 0.051 & 0.023 & 0.112 & 0.065 & 0.020 & 0.074 & 0.484 & 0.031 & 0.081 \\
\hline Aggregate 2 & 0.180 & 0.053 & 0.104 & 0.063 & 0.174 & 0.208 & 0.084 & 0.043 & 0.032 & 0.058 \\
\hline
\end{tabular}

Source: Authors' calculations in model (2). 
Volatility, Persistence and Variance Explained by Common Factors, Cross-Sector Breakdown (log monthly changes)

\begin{tabular}{|c|c|c|c|c|c|}
\hline & Durables & Semi-durables & Non-durables & Food & Services \\
\hline \multicolumn{6}{|c|}{ Volatility (standard deviations in pp.) } \\
\hline Aggregate & 0.204 & 0.128 & 0.171 & 0.218 & 0.199 \\
\hline Country & 0.116 & 0.076 & 0.136 & 0.180 & 0.096 \\
\hline Sector & 0.094 & 0.069 & 0.263 & 0.169 & 0.060 \\
\hline Country-sector & 0.183 & 0.124 & 0.235 & 0.252 & 0.106 \\
\hline Idiosyncratic & 0.533 & 0.400 & 0.651 & 0.952 & 0.434 \\
\hline COICOP & 0.199 & 0.128 & 0.265 & 0.406 & 0.146 \\
\hline \multicolumn{6}{|c|}{ Persistence, AR(1) coefficient } \\
\hline Aggregate & 0.976 & 0.975 & 0.973 & 0.974 & 0.974 \\
\hline Country & 0.180 & 0.613 & 0.615 & 0.620 & 0.624 \\
\hline Sector & 0.169 & 0.081 & 0.518 & 0.577 & 0.435 \\
\hline Country-sector & 0.252 & 0.105 & 0.267 & 0.308 & 0.226 \\
\hline Idiosyncratic & 0.952 & 0.009 & 0.081 & 0.124 & 0.066 \\
\hline COICOP & 0.406 & 0.027 & 0.125 & 0.316 & 0.122 \\
\hline \multicolumn{6}{|c|}{ Variance explained (in \%) } \\
\hline Aggregate & 16.6 & 18.2 & 11.1 & 11.3 & 23.9 \\
\hline Country & 5.9 & 6.5 & 6.7 & 5.6 & 6.9 \\
\hline Sector & 2.2 & 2.4 & 6.1 & 4.3 & 1.5 \\
\hline Country-sector & 11.1 & 9.0 & 9.3 & 9.7 & 5.8 \\
\hline Idiosyncratic & 64.0 & 63.8 & 66.8 & 68.9 & 61.9 \\
\hline COICOP & 10.7 & 9.8 & 11.9 & 13.4 & 9.7 \\
\hline \multicolumn{6}{|c|}{ Squared loadings at two aggregate factors } \\
\hline Aggregate 1 & 0.175 & 0.209 & 0.102 & 0.111 & 0.403 \\
\hline Aggregate 2 & 0.084 & 0.116 & 0.113 & 0.150 & 0.537 \\
\hline
\end{tabular}

Source: Authors' calculations in model (2). 


\section{References}

Allard, C. (2007). Inflation in Poland: How Much Can Globalization Explain? International Monetary Fund. Working Papers No. 41, https://doi.org/10.5089/9781451866056.001

Altissimo, F., Benigno, P., Palenzuela, D. R. (2011). Inflation Differentials in a Currency Area: Facts, Explanations and Policy. Open Economies Review, 22(2), 189-233, https://doi.org/10.1007/ s11079-010-9189-6

Bai, J., Ng, S. (2002). Determining the Number of Factors in Approximate Factor Models. Econometrica, 70(1), 191-221, https://doi.org/10.1111/1468-0262.00273

Beck, G. W., Hubrich, K., Marcellino, M. (2009). Regional Inflation Dynamics within and across Euro Area Countries and a Comparison with the United States. Economic Policy, 24(57), 141-184, https://doi.org/10.1111/j.1468-0327.2009.00214.x

Beck, G. W., Hubrich, K., Marcellino, M. (2011). On the Importance of Sectoral and Regional Shocks for Price-Setting. Centre for Economic Policy Research. Discussion Papers No. 8357.

Bils, M., Klenow, P. J. (2004). Some Evidence on the Importance of Sticky Prices. Journal of Political Economy, 112(5), 947-985, https://doi.org/10.1086/422559

Boivin, J., Giannoni, M. P., Mihov, I. (2009). Sticky Prices and Monetary Policy: Evidence from Disaggregated US Data. American Economic Review, 99(1), 350-384, https://doi. org/10.1257/aer.99.1.350

Borio, C. E., Filardo, A. (2007). Globalisation and Inflation: New Cross-Country Evidence on the Global Determinants of Domestic Inflation. Bank for International Settlements. Working Papers No. 227, https://doi.org/10.2139/ssrn.1013577

Choueiri, N., Ohnsorge, F., van Elkan, R. (2008). Inflation Differentials in the EU: A Common (Factors) Approach with Implications for EU8 Euro Adoption Prospects. International Monetary Fund. Working Papers No. 21.

Ciccarelli M., Mojon B. (2010). Global Inflation. The Review of Economics and Statistics, MIT Press, 92(3), 524-535 (prev. ECB Working Paper 2005 No. 537), https://doi.org/10.1162/ rest_a_00008

Dabusinskas A., Randveer, M. (2006). Comparison of Pricing Behaviour of Firms in the Euro Area and Estonia. Bank of Estonia. Working Papers No. 8.

European Commission (2013). European Economy. Member States'Energy Dependence: An Indicator-Based Assessment. Occasional Papers No. 145, April 2013.

Forni, M., Hallin, M., Lippi, M., Reichlin, L. (2000). The Generalized Dynamic-Factor Model: Identification and Estimation. The Review of Economics and Statistics, 82(4), 540-554, https://doi.org/10.1162/003465300559037

Hakkio, C. S. (2009). Global Inflation Dynamics. Federal Reserve Bank of Kansas City. Research Working Papers No. RWP 09-01, https://doi.org/10.2139/ssrn.1335348

Halka, A., Kotlowski, J. (2014). Does Domestic Output Gap Matter for Inflation in a Small Open Economy? Eastern European Economics, 52(3), 89-107, https://doi.org/10.2753/ eee0012-8775520305

Halka, A., Szafranski, G. (2015). What Common Factors Are Driving Inflation in CEE Countries. NBP Working Papers No. 225, https://www.nbp.pl/publikacje/materialy_i_studia/225_en.pdf

Kaufmann, D., Lein, S. M. (2013). Sticky Prices or Rational Inattention - What Can We Learn from Sectoral Price Data? European Economic Review, 64, 384-394, https://doi.org/10.1016/j. euroecorev.2013.10.001 
Krusper, B. (2012). The Role of External and Country Specific Factors in Hungarian Inflation Developments. Magyar Nemzeti Bank. Working Paper No. 5.

Mackowiak, B. (2006). How Much of the Macroeconomic Variation in Eastern Europe Is Attributable to External Shocks? Comparative Economic Studies, 48(3), 523-544, https:// doi.org/10.1057/palgrave.ces.8100143

Mackowiak, B., Moench, E., Wiederholt, M. (2009). Sectoral Price Data and Models of Price Setting. Journal of Monetary Economics, 56, 78-99, https://doi.org/10.1016/j. jmoneco.2009.06.012

Mackowiak, B., Wiederholt, M. (2009). Optimal Sticky Prices under Rational Inattention. American Economic Review, 99(3), 769-803, https://doi.org/10.1257/aer.99.3.769

Monacelli, T., Sala L. (2009). The International Dimension of Inflation: Evidence from Disaggregated Consumer Price Data. Journal of Money, Credit and Banking, Supplement to 41(1), 101-120, https://doi.org/10.1111/j.1538-4616.2008.00200.x

Pehnelt, G. (2007). Globalisation and Inflation in OECD Countries. European Centre for International Political Economy. Brussels Working Paper No. 4.

Stavrev, E. (2009). Forces Driving Inflation in the New EU10 Members. International Monetary Fund. Working Papers No. 51, https://doi.org/10.5089/9781451871999.001

Stock, J., Watson, M. (2002). Macroeconomic Forecasting Using Diffusion Indexes. Journal of Business and Economic Statistics, 20(2), 147-162, https://doi.

org/10.1198/073500102317351921 